\title{
Compounds Extracted from Larch, Birch bark, Douglas Fir, and Alder Woods with Four Different Solvents: Effects on Five Skin-related Microbes
}

\author{
Anja Schuster, ${ }^{*}{ }^{1}$ Nina Ortmayr, ${ }^{1}$ Gertie Janneke Oostingh, and Bettina Stelzhammer
}

\begin{abstract}
Wood is an important natural resource, and the extracts of specific wood species might have growth-inhibiting effects on certain microbes. This property can be used in the pharmaceutical industry to develop phytochemical-based medicine to treat skin infections. Thus far, methanol, intrinsically toxic, has been the main solvent used for extraction of soluble wood compounds. In this study, the focus was placed on biocompatible solvents, including dimethyl sulfoxide, distilled water, and glycerin, in addition to methanol used to extract compounds from larch, birch bark, Douglas fir, and alder wood sawdust. Microbial growth was tested on four different bacterial strains and one type of fungi representing species that can affect the skin. The results revealed intrinsic toxicity of biocompatible solvents at low concentrations as well as an additive or synergistic effect of wood extracts. In particular, larch and birch extracts strongly decreased microbial growth. In addition, interference of the extract color on the measurements was observed, which must be taken into account to ensure correct analysis of the data. In conclusion, biocompatible solvents in conjunction with larch and birch extracts exhibited antimicrobial effects. The importance of solvent toxicity and background staining were highlighted to determine potential antimicrobial effects.
\end{abstract}

Keywords: Wood extracts; Microbial growth; Biocompatible solvents; Intrinsic solvent toxicity; Extract background staining

Contact information: Biomedical Sciences, Salzburg University of Applied Sciences, Puch/Salzburg, Austria; 1: shared first author; *Corresponding author: anja.schuster@fh-salzburg.ac.at

\section{INTRODUCTION}

Wood is an important natural renewable resource, thereby posing a number of clear advantages over compounds that are chemically produced. Therefore, wood is regularly used as a building material. Other uses of wood and wood products are integrated in everyday life, such as the use of wood for natural fiber-reinforced composites, nanocellulose, or in biorefineries. Nevertheless, the perception of novel wood-containing products can be diverse and also dependent on the information available on the advantages and disadvantages of these products (Stern et al. 2018). In several cases, the use of wood in areas with an increased necessity for high hygienic standards, such as for butcheries (Gilbert and Watson 1971) or health care environments, has been reduced due to hygiene concerns. However, other studies have shown that wood is more frequently used as an appropriate material compared to other materials (Soares et al. 2012; Goh et al. 2014), although plastic is in some cases by no means preferable over wood (Carpentier 1997). Wood has several characteristics reducing the potential of microbes to spread and grow on its surface, such as the rapid dehydration of bacteria on wood surfaces (Kavian-Jahromi et al. 2015). In addition, it is known that certain wood species also contain compounds that 
actively reduce the growth of microbes (Roy et al. 2008; Plumed-Ferrer et al. 2013; VainioKaila et al. 2015; Vainio-Kaila et al. 2017). Therefore, the use of wood should always be considered in parallel to the use of synthetic materials, because wood might not only be equally good, but could also have beneficial characteristics. These additional benefits might also be present in the form of active antimicrobial substances present in wood, which could be of use for cosmetic or medical applications.

In this case, wood could be directly used, for example as powder dust in plasters and other topical applications. Nevertheless, the use of wood extracts has added benefits. Extracts can be added to creams or to bathing essences for topical applications; and also they can be added to liquids or tablets for oral applications. Previous studies have often used methanol as a solvent to test the antimicrobial effects (Laireiter et al. 2014; Gazoni et al. 2018; Wagner et al. 2019) because methanol has a high capacity to dissolve hydrophilic and certain hydrophobic compounds. However, for the use of extracts in medical applications, biocompatible and/or biological solvents would be preferable. To investigate the efficacy of biocompatible solvents in extracting wood compounds, the present study included the solvents dimethyl sulfoxide (DMSO), distilled water, and glycerin in this study. The DMSO, used as a polar, aprotic solvent miscible with water and able to dissolve an enormous catalog of polar and nonpolar small molecules, has penetration-enhancing properties and is employed in a number of topical pharmacological applications (Capriotti and Capriotti 2012). Distilled water dissolves hydrophilic compounds only; however, this disadvantage is balanced by the fact that distilled water is a biologically well-tolerated agent, reducing mixture toxicity and side-effects. Glycerin was chosen as a solvent due to its wide range of advantages including biocompatibility, non-toxicity, as well as its bacteriostatic and fungostatic properties (Padmawar and Bhadoriya 2018).

Unfortunately, as soon as a solvent is used for extraction, this solvent could directly affect the microbes to be tested or introduce the possibility of a mixture toxicity (Timm et al. 2013). These effects are difficult to analyze, because they are not necessarily an additive effect, but can be synergistic or antagonistic. Such effects can in some cases be beneficial, whereby it is important to understand the potential of the solvents to study the effects of an extract obtained with these solvents. To bypass the solvent effect, passive dosing systems have been developed to allowing the omission of solvents, whereby an inert polymer is used as a reservoir loaded with the test substance providing defined and constant freely dissolved concentrations by also eliminating spiking with co-solvents (Smith et al. 2010).

The use of wood extracts with defined anti-microbial capacities has a great promise for cosmetic and medical applications. On the one hand, wood extracts could be added to topical creams to avoid microbial growth in the cream and thereby improve the shelf life of these cosmetics. The choice of extracting agent is thereby of main importance, because only the use of biological extracting agents, such as distilled water or glycerin, allows a cream to be sold as a biological product. In contrast, topical agents with defined antimicrobial capacities can also be used to treat defined skin infections. This would reduce the amount of antibiotics used and thereby aid in the reduction of the formation of resistant bacterial strains.

To date, no approved drug is available on the market using wood extracts as antimicrobial agents. However, in the field of wound repair, the first phytochemical based drug called Episalvan has been approved in 2016 (Scheffler 2019). Episalvan is a drug containing the triterpene-rich, purified dry extract from the bark of Betula pendula and $B$. pubescens using $\mathrm{n}$-heptane as solvent. Its indication includes treatment of superficial skin wounds and II-a-degree burn wounds to the skin of adults (Scheffler 2019). In addition, 
phase 2 clinical studies are currently performed with Episalvan gel or Oleogel-S10 for faster re-epithelialization of wounds in Epidermolysis bullosa patients (Schwieger-Briel et al. 2019).

The sophisticated composition of the bark as well as the wood of the trees, which protects them from various microbes, might pose a suitable source of compounds to develop phytochemical extracts for topical application to deter skin pathogens and maintain skin health. Therefore, the aim of this study was to use different solvents for the extraction of soluble components from different kinds of wood and to test these extracts for their antimicrobial capacities on five different skin-related strains.

\section{EXPERIMENTAL}

\section{Materials}

Extracting agents

The solvents used for isolation of extractives were $\mathrm{MeOH}$, distilled water, DMSO, and glycerin. The MeOH (Fa. Merck KG, Darmstadt, Germany) was used as a reference solvent for extraction of hydrophilic and certain hydrophobic compounds. The DMSO (AppliChem GmbH, Darmstadt, Germany), a polar aprotic solvent, was used due to its properties as a vehicle for topical applications that are frequently compounded with antifungal medications. Therefore, it represents a suitable solvent for extracting compounds used for medical applications. Distilled water (Fresenius Kabi GmbH, Bad Homberg, Germany) was chosen as a natural solvent, dissolving hydrophilic compounds only. The glycerin (Serva Electorphoresis GmbH, Heidelberg, Germany) was chosen as a known 'alcohol-free', non-toxic alternative in preparing botanical extractions.

\section{Wood species and extracts}

The wood species used in this study included larch (Larix decidua) from a not overgrown branch, birch (Betula pendula) bark, Douglas fir (Pseudotsuga menziesii), and alder (Alnus glutinosa) wood as well as alder bark. The wood was ground to sawdust with a cutting mill (Retsch, Inc., Haan, Germany) and a screen perforation of $1 \mathrm{~mm}$.

Extractions were performed by addition of $1 \mathrm{~g}$ of sawdust to $10 \mathrm{~mL}$ of pure solvent (MeOH, distilled water, DMSO, or glycerin) on a shaker, with 1000 rotations per min for $24 \mathrm{~h}$ at room temperature as described in Wagner et al. (2019). After incubation, the extract was sterile filtered using $0.45-\mu \mathrm{m}$ Millex ${ }^{\circ} \mathrm{GS}$ syringe filters (Merck MILLIPORE, Burlington, MA, USA). The extracts were kept shielded from light at $8{ }^{\circ} \mathrm{C}$ until use.

\section{Test microorganisms}

The analysis of the potential antimicrobial activities was performed using five strains, four bacterial strains, and one fungus that cause typical clinical diseases. Staphylococcus aureus (ATCC®25923, Gram-positive bacterium), Escherichia coli (ATCC®25922, Gram-negative bacterium), Staphylococcus epidermidis (ATCC®12228), and Candida albicans (ATCC®10231, yeast) were obtained from American Type Culture Collection (ATCC®; Dartford, England). Cutibacterium acnes (Gram-positive bacterium) was obtained from the microbiology laboratory of the University Hospital in Salzburg (Austria). Their specificity was confirmed by MALDI-TOF - VITEK® MS (Biomerieux, Vienna, Austria). 


\section{Methods}

Toxicity test

To determine the toxicity of the solvents, a dilution series was performed for each solvent using volume concentrations of 2.5, 5, 7.5, 10, and $12.5 \% \mathrm{v} / \mathrm{v}$ of the solvents in broth. Pure broth was used as a control for normal growth. Brain Heart Broth (bioMerieux SA, Mercy-lÉtoile, France) was used for S. aureus, E. coli, S. epidermidis, and C. albicans. The $C$. acnes was tested in a thio-glycolate broth and incubated anaerobically. The strains were directly inoculated into the broth at McFarland (McF) of 0.5 for S. aureus, E. coli, $S$. epidermidis, and A. urines; and $\mathrm{McF}$ of 3 and 2 for $C$. acnes and $C$. albicans, respectively. The $\mathrm{McF}$ for each strain was determined using the Densicheck® (bioMerieux, Inc., Durham, NC, USA). The optical density (OD) was measured using a Tecan Infinite F200 plate reader (Tecan Austria $\mathrm{GmbH}$, Grödig, Austria) at $600 \mathrm{~nm}$ at time 0 and after 1, 2, 3, 4,5 , and 6 h incubation at $37^{\circ} \mathrm{C}$. The OD for $C$. acnes was measured after $0,2.5,5,7.5$, $25,27.5$, and $30 \mathrm{~h}$.

\section{Detection of the antimicrobial effects of wood materials}

For the detection of antimicrobial properties of wood extracts, the broth growth test was used. To allow for a comparison between the solvents, a uniform solvent concentration of $5 \% \mathrm{v} / \mathrm{v}$ in broth was chosen. Extracts used for the broth growth test included larch, birch bark, Douglas fir, alder wood, and alder bark. Controls were performed using broth only to control for the natural growth of the strains, broth with solvent to control for the toxicity of the solvent, and broth with solvent and extract, to control for the interference of the extract color on the measurements. The strains were directly inoculated into the broth, and the optical density was measured as described above. To avoid false positive results due to the interference of the extract color during the OD measurement, the control values obtained from broth with solvent and extract over time were subtracted from the results of the broth growth test. Furthermore, the results were normalized against the $0 \mathrm{~h}$ measurements to account for different starting OD values at the $0 \mathrm{~h}$ time point and possible interactions of the extracts and the strains.

\section{Data analysis}

For statistical analysis, the students t-test, Friedman test (for analysis across the time points), two-way analysis of variance (ANOVA) using match values (for analysis of individual time points), and multiple comparison against the control were performed. Statistics was performed using GraphPad Prism 8.3.0 software (GraphPad Software, San Diego, CA, USA).

\section{RESULTS AND DISCUSSIONS}

\section{Toxicity Test of Solvents}

The toxicity of the solvents was tested at five different volume concentrations to determine the effect of the solvents on the growth of the bacterial and fungal strains. In Table 1, the OD of the individual strains at the maximal incubation time of $30 \mathrm{~h}$ for $C$. acnes and $6 \mathrm{~h}$ for all other strains is shown in relation to the volume concentration of the solvent. At a solvent concentration of $5 \% \mathrm{v} / \mathrm{v}$, methanol significantly decreased the growth of all strains except $C$. acnes; distilled water decreased the growth of $S$. epidermidis; DMSO decreased the growth of all strains; and glycerin decreased the growth of C. acnes, 
S. aureus, and S. epidermidis. Even though a significant inhibition was observed for all solvents at a concentration of $5 \% \mathrm{v} / \mathrm{v}$, a biological relevant inhibition was considered at an inhibition of greater than $10 \%$, which was observed for $\mathrm{MeOH}$, DMSO, and glycerin in a limited number of strains (Table 1 , bold and italicized values).

Table 1. Solvent Toxicity Data of Bacterial Strains with Solvents at the Maximal Incubation Time (30 h for $C$. acnes and $6 \mathrm{~h}$ for All Other Strains). Results are displayed as optical density measurement.

\begin{tabular}{|c|c|c|c|c|c|}
\hline & $\begin{array}{l}\text { Conc. } \\
(v / v)\end{array}$ & $\mathrm{MeOH}$ & Distilled water & DMSO & Glycerin \\
\hline \multirow{6}{*}{ 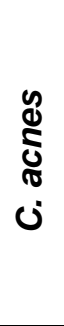 } & $0.0 \%$ & $0.980 \pm 0.018$ & $0.980 \pm 0.018$ & $0.980 \pm 0.018$ & $0.980 \pm 0.018$ \\
\hline & $2.5 \%$ & $1.027 \pm 0.051$ & $1.030 \pm 0.063$ & $1.082 \pm 0.018$ & $0.893 \pm 0.035$ \\
\hline & $5.0 \%$ & $1.006 \pm 0.003$ & $1.007 \pm 0.007$ & $1.069 \pm 0.029$ & $0.894 \pm 0.016$ \\
\hline & $7.5 \%$ & $0.83 \pm 0.056$ & $0.995 \pm 0.035$ & $0.932 \pm 0.024$ & $0.862 \pm 0.018$ \\
\hline & $10.0 \%$ & $1.016 \pm 0.013$ & $0.990 \pm 0.034$ & $0.795 \pm 0.007$ & $0.856 \pm 0.021$ \\
\hline & $12.5 \%$ & $0.955 \pm 0.017$ & $1.018 \pm 0.062$ & $0.651 \pm 0.015$ & $0.834 \pm 0.012$ \\
\hline \multirow{6}{*}{$\begin{array}{l}\text { ఫे } \\
\text { 山े }\end{array}$} & $0.0 \%$ & $0.590 \pm 0.021$ & $0.590 \pm 0.021$ & $0.590 \pm 0.021$ & $0.590 \pm 0.021$ \\
\hline & $2.5 \%$ & $0.528 \pm 0.006$ & $0.563 \pm 0.004$ & $0.564 \pm 0.002$ & $0.542 \pm 0.073$ \\
\hline & $5.0 \%$ & $0.473 \pm 0.051$ & $0.570 \pm 0.020$ & $0.484 \pm 0.007$ & $0.530 \pm 0.037$ \\
\hline & $7.5 \%$ & $0.362 \pm 0.100$ & $0.567 \pm 0.012$ & $0.449 \pm 0.009$ & $0.521 \pm 0.005$ \\
\hline & $10.0 \%$ & $0.348 \pm 0.141$ & $0.571 \pm 0.007$ & $0.372 \pm 0.010$ & $0.448 \pm 0.049$ \\
\hline & $12.5 \%$ & $0.333 \pm 0.131$ & $0.566 \pm 0.025$ & $0.275 \pm 0.039$ & $0.408 \pm 0.012$ \\
\hline \multirow{6}{*}{ 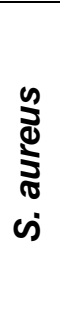 } & $0.0 \%$ & $0.572 \pm 0.012$ & $0.572 \pm 0.012$ & $0.572 \pm 0.012$ & $0.572 \pm 0.012$ \\
\hline & $2.5 \%$ & $0.559 \pm 0.003$ & $0.519 \pm 0.012$ & $0.512 \pm 0.015$ & $0.541 \pm 0.007$ \\
\hline & $5.0 \%$ & $0.526 \pm 0.017$ & $0.523 \pm 0.033$ & $0.451 \pm 0.028$ & $0.504 \pm 0.003$ \\
\hline & $7.5 \%$ & $0.501 \pm 0.011$ & $0.501 \pm 0.007$ & $0.392 \pm 0.011$ & $0.467 \pm 0.013$ \\
\hline & $10.0 \%$ & $0.455 \pm 0.010$ & $0.522 \pm 0.007$ & $0.319 \pm 0.005$ & $0.458 \pm 0.016$ \\
\hline & $12.5 \%$ & $0.406 \pm 0.025$ & $0.536 \pm 0.026$ & $0.281 \pm 0.007$ & $0.424 \pm 0.019$ \\
\hline \multirow{6}{*}{ 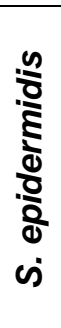 } & $0.0 \%$ & $0.358 \pm 0.006$ & $0.358 \pm 0.006$ & $0.358 \pm 0.006$ & $0.358 \pm 0.006$ \\
\hline & $2.5 \%$ & $0.387 \pm 0.014$ & $0.326 \pm 0.006$ & $0.309 \pm 0.012$ & $0.333 \pm 0.008$ \\
\hline & $5.0 \%$ & $0.388 \pm 0.014$ & $0.324 \pm 0.008$ & $0.278 \pm 0.010$ & $0.308 \pm 0.005$ \\
\hline & $7.5 \%$ & $0.352 \pm 0.016$ & $0.327 \pm 0.008$ & $0.242 \pm 0.003$ & $0.287 \pm 0.006$ \\
\hline & $10.0 \%$ & $0.295 \pm 0.021$ & $0.333 \pm 0.009$ & $0.208 \pm 0.004$ & $0.288 \pm 0.009$ \\
\hline & $12.5 \%$ & $0.238 \pm 0.015$ & $0.357 \pm 0.006$ & $0.191 \pm 0.003$ & $0.287 \pm 0.004$ \\
\hline \multirow{6}{*}{ 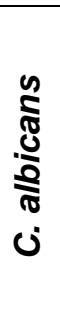 } & $0.0 \%$ & $0.373 \pm 0.022$ & $0.373 \pm 0.022$ & $0.373 \pm 0.022$ & $0.373 \pm 0.022$ \\
\hline & $2.5 \%$ & $0.338 \pm 0.025$ & $0.356 \pm 0.005$ & $0.311 \pm 0.033$ & $0.378 \pm 0.026$ \\
\hline & $5.0 \%$ & $0.331 \pm 0.008$ & $0.347 \pm 0.025$ & $0.256 \pm 0.009$ & $0.345 \pm 0.016$ \\
\hline & $7.5 \%$ & $0.309 \pm 0.003$ & $0.356 \pm 0.027$ & $0.201 \pm 0.011$ & $0.304 \pm 0.009$ \\
\hline & $10.0 \%$ & $0.250 \pm 0.006$ & $0.338 \pm 0.017$ & $0.161 \pm 0.009$ & $0.302 \pm 0.020$ \\
\hline & $12.5 \%$ & $0.209 \pm 0.011$ & $0.345 \pm 0.013$ & $0.154 \pm 0.006$ & $0.269 \pm 0.023$ \\
\hline
\end{tabular}

Values shown are the mean \pm standard deviation of three independently performed measurements. Bold print indicates a statistically significant change $(p<0.05)$ when compared to the untreated control $(0 \%)$, bold and italics print indicate a statistically significant change that is also biologically relevant (more than 10\% difference compared to the untreated control). 

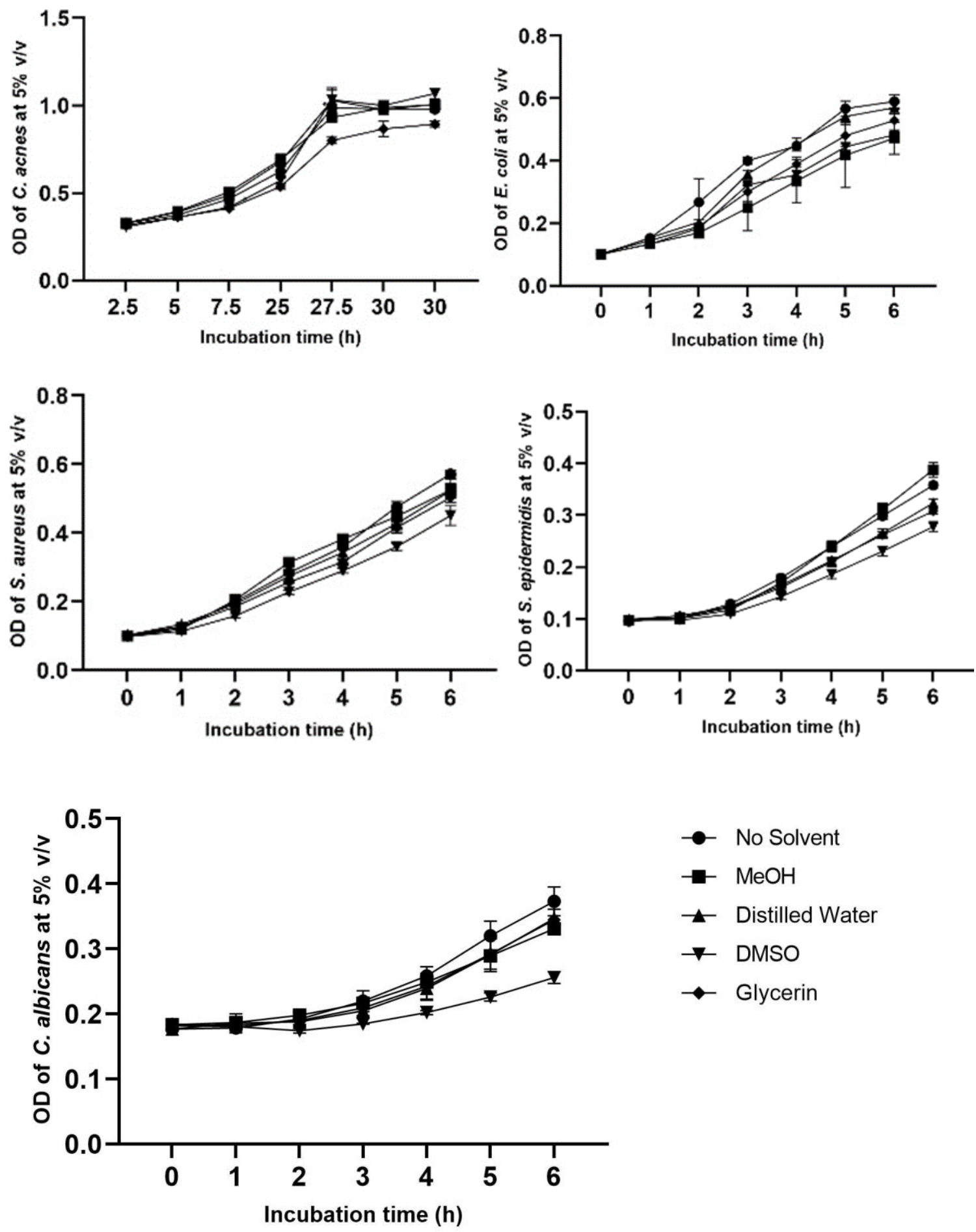

Fig. 1. The time course of the toxicity test at a solvent concentration of $5 \% \mathrm{v} / \mathrm{v}$ is shown for each strain. Significant inhibition of growth across the time points can be observed with the solvent DMSO in E.coli $(p<0.01)$, A. aureus ( $<0.02)$, S. epidermidis $(p<0.01)$, and $C$. albicans $(<$ $0.02)$ as well as with the solvent $\mathrm{MeOH}$ in $E$. coli $(\mathrm{p}<0.001)$. Values shown are the mean \pm standard deviation of three independently performed measurements. 

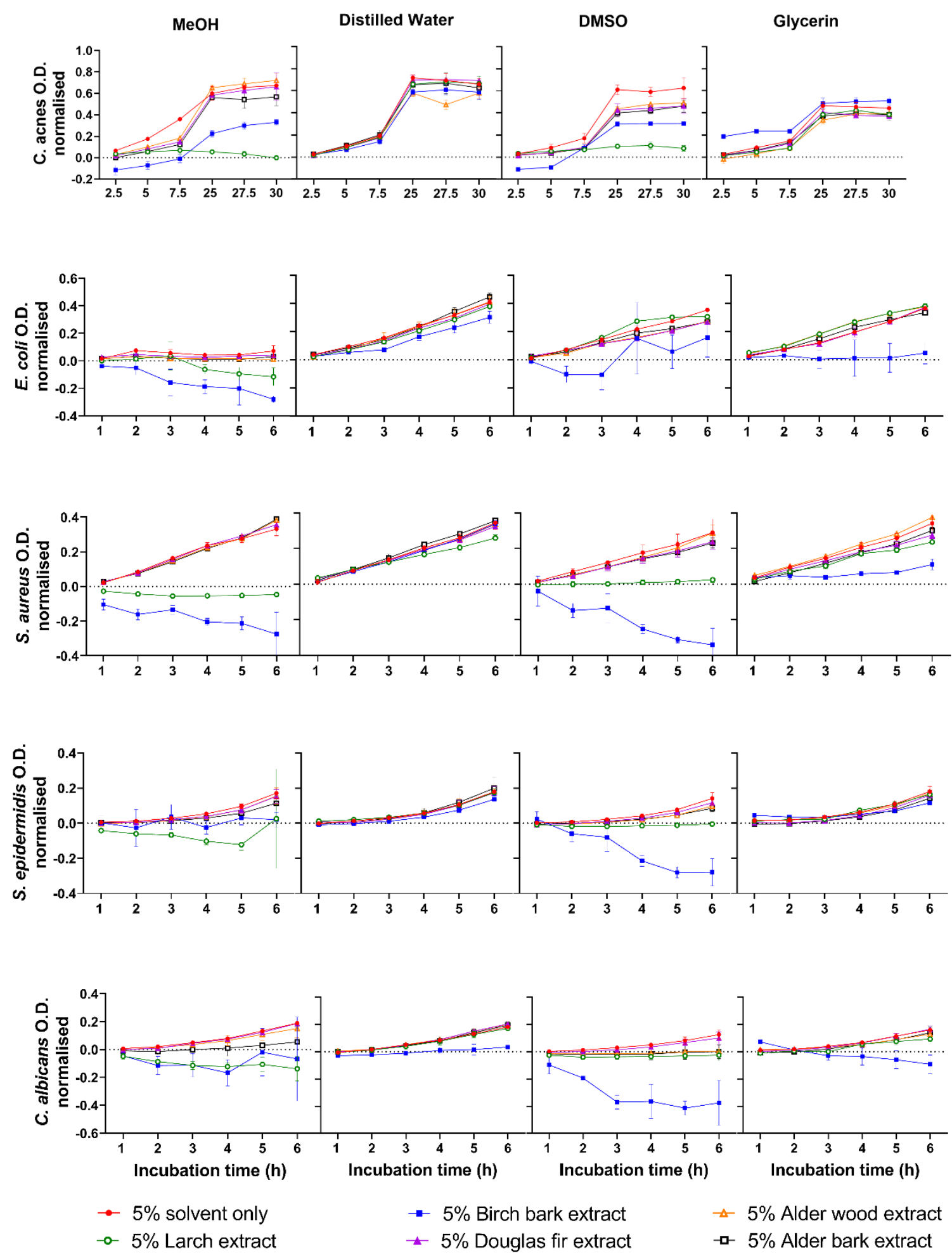

Fig. 2. Microbial growth over time for each solvent with different wood extracts. Values are subtracted from background color of the extract and normalized against OD at $0 \mathrm{~h}$. Significance was analyzed across all time points and compared to 'solvent only' control.

MeOH: Larch (C. acnes ${ }^{\star \star}$, E. coli ${ }^{*}$, S. aureus ${ }^{\star}, S$. epidermidis ${ }^{\star \star \star \star}$, and C. albicans $\left.{ }^{\star \star \star \star}\right)$, Birch bark (C. acnes ${ }^{\star *}, E$. coli $i^{* \star *}, S$. aureus ${ }^{* *}$, S. epidermidis ${ }^{*}$, and C. albicans $\left.{ }^{\star * *}\right)$, Alder wood (C. albicans $\left.{ }^{*}\right)$; (Caption continued next page). 
Distilled water: Larch (E. coli $\left.{ }^{\star}\right)$, Birch bark (C. acnes*, E. coli $i^{* *}, S$. epidermidis*, and C. albicans ${ }^{\star}$;

DMSO: Larch (C. acnes*, S. aureus* ${ }^{\star *}$ S. epidermidis ${ }^{* *}$, and C. albicans**), Birch bark (C. acnes $^{\star \star}$, E. coli ${ }^{* \star}$, S. aureus ${ }^{\star \star \star *}$, S. epidermidis ${ }^{\star *}$, and C. albicans $\left.{ }^{\star \star \star \star}\right)$, Alder bark (C. acnes ${ }^{\star}, C$. albicans*); Glycerin: Larch (C. albicans*), Birch bark (S. aureus ${ }^{*}, C$. albicans*), Alder wood (C. acnes $^{*}$ ), Alder bark (S. epidermidis ${ }^{* *}, C$. albicans ${ }^{*}$ ). Shown is the mean \pm standard deviation of 3 independently performed measurements. ${ }^{*} \mathrm{p}<0.05$, ${ }^{* \star} \mathrm{p}<0.01$, ${ }^{* \star} \mathrm{p}<0.001$, and ${ }^{* \star * *} \mathrm{p}<0.0001$

Additionally, a greater amount of wood compound concentration can be expected in a $5 \% \mathrm{v} / \mathrm{v}$ concentration over $2.5 \% \mathrm{v} / \mathrm{v}$; therefore, this concentration was chosen for further studies. To analyze the toxicological effect over time, a time course study was performed for all strains incubated with the different solvents at $5 \% \mathrm{v} / \mathrm{v}$ (Fig. 1). Significant inhibition of growth across the time points was observed for DMSO in all strains except $C$. acnes and for $\mathrm{MeOH}$ in E. coli (Fig. 1).

\section{Antimicrobial Effects of Wood Materials}

The antimicrobial effect of the extract from different wood species was tested using a broth growth test in all bacterial and fungal strains with the four solvents $\mathrm{MeOH}$, distilled water, DMSO, and glycerin. A time course study was performed to determine the inhibition of growth over $30 \mathrm{~h}$ for $C$. acnes and $6 \mathrm{~h}$ for all other strains, and the results reported were compared against solvent without extract across the time points (significant overall inhibition across time points) (Fig. 2). As described in the 'Experimental' section, the values shown in Fig. 2 were subtracted from the background color of the wood extracts and normalized against the OD of the first measurement at $0 \mathrm{~h}$. When using $\mathrm{MeOH}$ as a solvent, significant inhibition of growth across the time points was observed with the wood extracts birch bark and larch in all strains, and similar observation for alder bark in $C$. albicans. The distilled water as a solvent was effective in compound extraction from birch bark, which significantly inhibited growth of all strains except $S$. aureus and was effective in compound extraction from larch extracts in E. coli. When using DMSO as a solvent, birch bark extracts showed significant antimicrobial effects in all strains, and also larch extracts in all strains except $E$. coli. Significance across the time points was also reached for alder bark in $C$. acnes and $C$. albicans. An antimicrobial effect of the wood extracts in glycerin was seen for larch in $C$. albicans, for birch bark in $S$. aureus and C. albicans, for alder wood in C. acnes, and for alder bark extracts in S. epidermidis and C. albicans (Fig. 2).

In Table 2, the statistical analysis for the antimicrobial broth growth test is shown for each individual time point and each solvent with the different wood. As described before, the solvents, except distilled water, intrinsically led to inhibition of growth (Fig. 1, Table 1). Therefore, the inhibition of growth compared to the solvent only, as shown in Fig. 2, will not only be caused by additive inhibitory effects, but are most likely due to synergistic inhibitory effects caused by the different compounds of the wood extracts.

The data showed that the antimicrobial effect of the wood extracts was dependent on the type of wood used in combination with the solvent, as well as the sensitivity of each strain towards the solvent and the extract. Overall, the study displayed that $\mathrm{MeOH}$ and DMSO wood extracts, specifically from larch and birch bark, were most effective in inhibiting bacterial growth across all strains. 
Table 2. Statistical Analysis of the Antimicrobial Broth Growth Test for Each Individual Time Point with the Different Extracts and Solvents

(a: $\mathrm{MeOH}, \mathrm{A} . \mathrm{D} ; \mathrm{b}: \mathrm{DMSO}$, glycerin)

\begin{tabular}{|c|c|c|c|c|c|c|c|c|c|c|c|}
\hline \multirow[t]{2}{*}{ a) } & & \multicolumn{5}{|c|}{$\mathrm{MeOH}$} & \multicolumn{5}{|c|}{ Distilled Water } \\
\hline & $\mathrm{h}$ & $\mathbf{L}^{+}$ & $\mathrm{B}^{+}$ & $\mathrm{D}^{+}$ & $A, w^{+}$ & $A, b^{+}$ & $\mathbf{L}$ & B & D & $A, w$ & $A, b$ \\
\hline \multirow{6}{*}{ 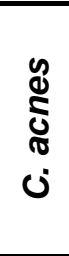 } & 2.5 & ns & * & * & * & $\star \star$ & ns & ns & ns & ns & ns \\
\hline & 5 & ** & ** & ** & $*$ & * & ns & ns & ns & ns & ns \\
\hline & 7.5 & $\star \star$ & $\star \star$ & $\star *$ & 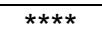 & $* \star \star \star *$ & ns & ns & ns & ns & ns \\
\hline & 25 & * & $\star \star$ & $\mathrm{ns}$ & ns & ns & ns & * & ns & * & ns \\
\hline & 28 & $\star \star \star * \star$ & $\star \star \star *$ & ns & ns & ns & ns & ns & ns & ns & ns \\
\hline & 30 & 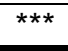 & $\star \star *$ & ns & ns & ns & ns & ns & ns & ns & ns \\
\hline \multirow{6}{*}{ 仓े } & 1 & $\mathrm{~ns}$ & * & $\mathrm{ns}$ & ns & $\mathrm{ns}$ & ns & $\mathrm{ns}$ & ns & ns & $\mathrm{ns}$ \\
\hline & 2 & $\mathrm{~ns}$ & * & ns & $\mathrm{ns}$ & ns & ns & $\star \star$ & ns & $\mathrm{ns}$ & $\mathrm{ns}$ \\
\hline & 3 & ns & ns & $\mathrm{ns}$ & ns & $\mathrm{ns}$ & ns & 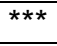 & ns & ns & ns \\
\hline & 4 & $\mathrm{~ns}$ & ${ }^{\star}$ & $\mathrm{ns}$ & $\mathrm{ns}$ & ${ }^{*}$ & ns & ${ }^{*}$ & $\mathrm{~ns}$ & ns & ns \\
\hline & 5 & ns & $\star \star$ & ns & ns & * & ns & * & $\mathrm{ns}$ & ns & ns \\
\hline & 6 & ns & ns & ns & ns & $\mathrm{ns}$ & ns & $\mathrm{ns}$ & ns & ns & ns \\
\hline \multirow{6}{*}{ 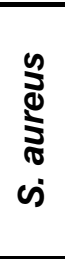 } & 1 & 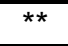 & * & ns & ns & $\mathrm{ns}$ & ns & ns & $\mathrm{ns}$ & $\mathrm{ns}$ & $\mathrm{ns}$ \\
\hline & 2 & ** & ** & $\mathrm{ns}$ & $\mathrm{ns}$ & $\mathrm{ns}$ & $\mathrm{ns}$ & $\mathrm{ns}$ & $\mathrm{ns}$ & $\mathrm{ns}$ & $\mathrm{ns}$ \\
\hline & 3 & ** & ** & ns & ns & ns & ns & ns & ns & ns & ns \\
\hline & 4 & $\star \star$ & 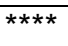 & $\mathrm{ns}$ & $\mathrm{ns}$ & $\mathrm{ns}$ & ns & $\mathrm{ns}$ & $\mathrm{ns}$ & $\mathrm{ns}$ & $\mathrm{ns}$ \\
\hline & 5 & ** & $\star \star \star$ & ns & ns & ns & ns & ns & $\mathrm{ns}$ & ns & ns \\
\hline & 6 & $\star \star$ & * & ns & ns & ns & ns & ns & $\mathrm{ns}$ & ns & ns \\
\hline \multirow{6}{*}{ 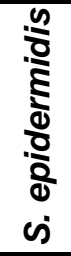 } & 1 & $\star \star$ & ns & $\mathrm{ns}$ & $\star \star$ & $\overline{n s}$ & ns & $\mathrm{ns}$ & $\overline{\mathrm{ns}}$ & $\mathrm{ns}$ & $\overline{n s}$ \\
\hline & 2 & $\star \star$ & ns & ns & * & ns & ns & $*$ & $\mathrm{~ns}$ & $\mathrm{~ns}$ & ns \\
\hline & 3 & * & ns & ns & * & ns & ns & * & ns & ns & ns \\
\hline & 4 & ** & ns & ns & ns & ns & ns & * & $\mathrm{ns}$ & ns & ns \\
\hline & 5 & $\star \star *$ & ns & ns & ns & ns & ns & ns & ns & ns & ns \\
\hline & 6 & ns & * & ns & ns & ns & $\mathrm{ns}$ & ns & $\mathrm{ns}$ & ns & $\mathrm{ns}$ \\
\hline \multirow{6}{*}{ 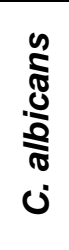 } & 1 & $\mathrm{~ns}$ & ns & $\mathrm{ns}$ & $\mathrm{ns}$ & $\mathrm{ns}$ & $\mathrm{ns}$ & ns & $\mathrm{ns}$ & $\mathrm{ns}$ & $\mathrm{ns}$ \\
\hline & 2 & $\star \star \star *$ & ns & ns & $\mathrm{ns}$ & ns & ns & * & $\mathrm{ns}$ & ns & ns \\
\hline & 3 & * & ns & $\mathrm{ns}$ & $\mathrm{ns}$ & $\mathrm{ns}$ & ns & ** & $\mathrm{ns}$ & $\mathrm{ns}$ & $\mathrm{ns}$ \\
\hline & 4 & $\star \star$ & ns & ns & $\mathrm{ns}$ & $\mathrm{ns}$ & ns & * & $\mathrm{ns}$ & $\mathrm{ns}$ & ns \\
\hline & 5 & * & $\mathrm{ns}$ & ns & $\mathrm{ns}$ & ns & ns & ns & $\mathrm{ns}$ & ns & ns \\
\hline & 6 & $\mathrm{~ns}$ & ns & ns & ns & ns & ns & $\mathrm{ns}$ & $\mathrm{ns}$ & $\mathrm{ns}$ & $\mathrm{ns}$ \\
\hline
\end{tabular}

+L: Larch; B: Birch bark; D: Douglas fir; A, w: Alder wood; A, b: Alder bark Values were calculated from three independently performed measurements; ${ }^{*} p<0.05,{ }^{\star *} p<0.01,{ }^{* \star *} p<0.001,{ }^{* \star * *} p<$ 0.0001

\begin{tabular}{|c|c|c|c|c|c|c|c|c|c|c|c|}
\hline b) & & \multicolumn{5}{|c|}{ DMSO } & \multicolumn{5}{|c|}{ Glycerin } \\
\hline & $\mathrm{h}$ & $\mathbf{L}$ & B & D & $A, w$ & $A, b$ & $\mathbf{L}$ & B & D & $A, w$ & $A, b$ \\
\hline \multirow{6}{*}{ 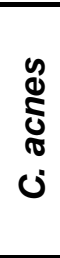 } & 2.5 & ns & 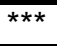 & ns & ns & ns & ns & $\star \star *$ & ns & ns & ns \\
\hline & 5 & ns & ** & ns & ns & ns & ns & ** & ns & ns & ns \\
\hline & 7.5 & ns & ns & ns & ns & ns & * & * & ns & ns & ns \\
\hline & 25 & $\star \star$ & $\star \star$ & * & * & $\star \star$ & ns & ns & ns & $\star$ & ns \\
\hline & 28 & $\star \star \star *$ & ** & * & ns & * & ns & ns & ns & ns & ns \\
\hline & 30 & * & ns & ns & ns & ns & ns & ns & ns & ns & ns \\
\hline \multirow{6}{*}{$\begin{array}{l}\text { نे } \\
\text { نे }\end{array}$} & 1 & $\mathrm{~ns}$ & $\mathrm{~ns}$ & $\mathrm{~ns}$ & $\mathrm{~ns}$ & $\mathrm{~ns}$ & $\mathrm{~ns}$ & ns & $\mathrm{ns}$ & $\mathrm{ns}$ & $\mathrm{ns}$ \\
\hline & 2 & ns & ns & ns & ns & ns & ns & ns & ns & ns & ns \\
\hline & 3 & ns & ns & ns & ns & ns & * & ns & ns & ${ }^{*}$ & ns \\
\hline & 4 & ns & ns & ns & ns & ns & ** & ns & ns & * & ns \\
\hline & 5 & ns & ns & * & $\star \star$ & * & * & ns & ns & * & ns \\
\hline & 6 & ns & ns & * & $\star \star$ & ** & ns & * & ns & ns & ns \\
\hline
\end{tabular}




\begin{tabular}{|c|c|c|c|c|c|c|c|c|c|c|c|}
\hline \multirow{6}{*}{ 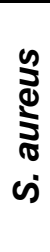 } & 1 & ns & $\mathrm{ns}$ & ns & ns & ns & ns & ns & ns & ns & $\mathrm{ns}$ \\
\hline & 2 & * & * & ns & ns & ns & ns & $\mathrm{ns}$ & ns & ns & $\mathrm{ns}$ \\
\hline & 3 & * & $\mathrm{ns}$ & ns & ns & ns & ns & ${ }^{*}$ & ns & ns & $\mathrm{ns}$ \\
\hline & 4 & * & $\star \star *$ & ns & ns & ns & ns & * & ns & ns & $\mathrm{ns}$ \\
\hline & 5 & ns & ** & ns & ns & ns & ns & * & ns & ns & $\mathrm{ns}$ \\
\hline & 6 & ns & ** & ns & ns & ns & ns & ** & ns & ns & $\mathrm{ns}$ \\
\hline \multirow{6}{*}{ 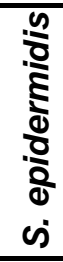 } & 1 & ns & ns & $\mathrm{ns}$ & ${ }^{*}$ & ${ }^{\star *}$ & ns & ns & ns & ns & $\mathrm{ns}$ \\
\hline & 2 & 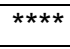 & ns & ns & * & 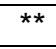 & ns & ns & ns & ns & $\mathrm{ns}$ \\
\hline & 3 & $\star * *$ & ns & ns & ** & * & ns & ns & ns & ns & $\mathrm{ns}$ \\
\hline & 4 & ** & ** & ns & * & * & ns & ns & ns & ns & $\mathrm{ns}$ \\
\hline & 5 & * & ** & ns & ns & ns & ns & ns & ns & ns & ns \\
\hline & 6 & * & * & $\mathrm{ns}$ & ns & ns & ns & ns & ns & ns & $\mathrm{ns}$ \\
\hline \multirow{6}{*}{ 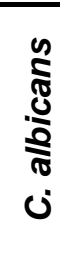 } & 1 & * & $\mathrm{ns}$ & $\mathrm{ns}$ & ns & ns & $\mathrm{ns}$ & ${ }^{*}$ & ns & ns & * \\
\hline & 2 & ** & $\star \star * * *$ & $\mathrm{~ns}$ & ns & ns & ${ }^{*}$ & ns & ns & ns & $\mathrm{ns}$ \\
\hline & 3 & * & ** & ns & * & ns & ns & ns & ns & ns & $\mathrm{ns}$ \\
\hline & 4 & ${ }^{\star}$ & ns & $\mathrm{ns}$ & ns & ns & ns & ns & ns & ns & $\mathrm{ns}$ \\
\hline & 5 & * & ** & $\mathrm{ns}$ & ns & ns & ns & $\mathrm{ns}$ & ns & ns & $\mathrm{ns}$ \\
\hline & 6 & * & ns & $\mathrm{ns}$ & $\mathrm{ns}$ & $\mathrm{ns}$ & $*$ & $*$ & ns & ns & $\mathrm{ns}$ \\
\hline
\end{tabular}

The antimicrobial activity of larch has been documented in a number of studies (Laireiter et al. 2014; Kavian-Jahromi et al. 2015; Wagner et al. 2019). In the authors' previous study, the composition of the larch bark extracts was characterized; polyphenols and its subgroup flavonoids were identified as the main component of the extract (Wagner et al. 2019). Among the active components of larch extracts, procyanidin, a class of flavonoids, acts as antibacterial agent by destroying the integrity and permeability of the cell wall and cell membrane, then affecting protein synthesis and binding to DNA in $S$. aureus (Li et al. 2017). In the outer bark of birch trees, the active compound betulin, a triterpene, was identified as the antibacterial agent and has been discussed in combined antibiotic therapy with commonly available antibiotics (Chung et al. 2011; Haque et al. 2014). However, a direct link of the active compound betulin to the results from the present study is not possible, since the chemical composition of birch bark extracts, including the betulin content, was not characterized. The antimicrobial effect of birch bark was also present in the biocompatible solvents glycerin and distilled water, a promising result that allows the use of these extracts in food, healthcare, and cosmetic products. In addition to the larch and birch bark extracts, positive results were achieved in $S$. epidermidis and $C$. acnes with alder bark extracts dissolved in DMSO and MeOH, respectively. This is in line with an in-depth study investigating the antimicrobial activity of 14 diarylheptanoids isolated from the bark of black and green alder against 12 bacterial species and eight fungal strains (Novaković et al. 2015). In this study, oregonin was identified as the most abundant compound in the chloroform/methanol extract that showed anti-mycotic activities, especially against candidiasis including C. albicans (Novaković et al. 2015).

The wood extracts from Douglas fir and alder wood exhibited negligible biologically relevant effects on the microbial growth in any of the strains measured. Limited information is available on the antimicrobial activity of wood extracts from Douglas fir. In a study comparing the effects of essential oils and methanol extracts from Douglas fir tested against anaerobic bacteria and yeast, it was shown that the methanol extracts of the heartwood of Douglas fir have no antimicrobial activity, whereas the essential oil of Douglas fir shows antimicrobial activity against Actinomyces bovis (Johnston et al. 2001). 
The lack of antimicrobial activity of these extracts could also be explained by the method of extraction used in this study. For comparative reasons, the authors kept the extracting methods consistent over the various solvents as well as the different wood types, which might result in different degrees of extracted compounds and further affect the extent of inhibition. Therefore, it can be assumed that the amount of substances, especially when using distilled water in the current setting for extraction, were limited in influencing microbial growth. For distilled water, the use of pressurized hot water to extract wood compounds, a method described by Ravber et al. should be considered for further studies in obtaining higher concentrations of compounds (Ravber et al. 2015). In addition, each type of wood might need specific conditions to dissolve the active components, which would need to be further refined. In this respect, an analysis of the extracted wood compounds comparing the different solvents and further antimicrobial testing of isolated component groups should be performed to identify the active antimicrobial wood component. This would also clarify if the effects observed were due to a combined effect of several compounds. In addition, host-pathogen co-culture assay should be performed to simultaneously measure the efficacy and tolerability of antimicrobial compounds and to mimic natural bacterial infections.

Taken together, the present results could show that biological and biocompatible extracting agents, such as distilled water, glycerin, and DMSO, were suitable to extract compounds from wood sawdust and show promising antimicrobial capacities in combination with specific wood types such as larch and birch bark. These extracts could be used in topical applications and as pharmaceuticals to treat skin infections as well as cosmetic ingredients to deter skin pathogens and maintain skin health. The diverse spectrum of antimicrobial activities from different wood types, and the use of biocompatible extracting agents make them promising candidates for the development of cosmetic products that deter dermatological pathogens.

\section{CONCLUSIONS}

1. Biocompatible solvents distilled water, DMSO, and glycerin were suitable extracting agents for wood compounds, which exhibited intrinsic antimicrobial activities at a $5 \%$ v/v concentration.

2. Wood extracts, especially from larch and birch bark, markedly inhibited microbial growth in an additive or synergistically manner to the biocompatible solvents. The effects observed in extracts from Douglas fir as well as alder wood were negligible.

3. It was shown that accurate results can be obtained even in cases where the extracts had significant coloration. It was possible to compensate for the effects of changes in color and optical measurements, as well as effects of solvent toxicity, when carrying out antimicrobial assays. 


\section{ACKNOWLEDGMENTS}

The authors are grateful for the financial support of the institutional Health Science Funding (Project Number: 7081_017). In addition, the authors thank the Department of Forest Products Technology and Timber Construction at the Salzburg University of Applied Sciences for providing the wood samples. The Department of Microbiology at the Salzburg University Hospital is acknowledged for providing some of the bacterial strains.

\section{REFERENCES CITED}

Capriotti, K., and Capriotti, J. A. (2012). "Dimethyl sulfoxide: History, chemistry, and clinical utility in dermatology," The Journal of Clinical and Aesthetic Dermatology 5(9), 24-26.

Carpentier, B. (1997). "Sanitary quality of meat chopping board surfaces: A bibliographical study," Food Microbiology 14(1), 31-37. DOI: 10.1006/fmic.1996.0061

Chung, P. Y., Navaratnam, P., and Chung, L. Y. (2011). "Synergistic antimicrobial activity between pentacyclic triterpenoids and antibiotics against Staphylococcus aureus strains," Annals of Clinical Microbiology and Antimicrobials 10, Article number 25. DOI: 10.1186/1476-0711-10-25

Gazoni, V. F., Balogun, S. O., Arunachalam, K., Oliveira, D. M., Filho, V. C., Lima, S. R., Colodel, E. M., Soares, I. M., Ascêncio, S. D., and Martins, D. T. D. O. (2018). "Assessment of toxicity and differential antimicrobial activity of methanol extract of rhizome of Simaba ferruginea A. St.-Hil. and its isolate canthin-6-one," Journal of Ethnopharmacology 223, 122-134. DOI: 10.1016/j.jep.2018.05.014

Gilbert, R. J., and Watson, H. M. (1971). "Some laboratory experiments on various meat preparation surfaces with regard to surface contamination and cleaning," International Journal of Food Science + Technology 6(2), 163-170. DOI: 10.1111/j.1365-2621.1971.tb01604.x

Goh, S. G., Leili, A.-H., Kuan, C. H., Loo, Y. Y., Lye, Y. L., Chang, W. S., Soopna, P., Najwa, M. S., Tang, J. Y. H., Yaya, R., et al. (2014). "Transmission of Listeria monocytogenes from raw chicken meat to cooked chicken meat through cutting boards," Food Control 37(1), 51-55. DOI: 10.1016/j.foodcont.2013.08.030

Haque, S., Nawrot, D. A., Alakurtti, S., Ghemtio, L., Yli-Kauhaluoma, J., and Tammela, P. (2014). "Screening and characterisation of antimicrobial properties of semisynthetic betulin derivatives," PLoS One 9(7), 1-9. DOI: 10.1371/journal.pone.0102696

Johnston, W. H., Karchesy, J. J., Constantine, G. H., and Craig, A. M. (2001).

"Antimicrobial activity of some Pacific Northwest woods against anaerobic bacteria and yeast," Phytotherapy Research: PTR 15(7), 586-588.

Kavian-Jahromi, N., Schagerl, L., Dürschmied, B., Enzinger, S., Schnabl, C., Schnabel, T., and Petutschnigg, A. (2015). "Comparison of the antibacterial effects of sapwood and heartwood of the larch tree focusing on the use in hygiene sensitive areas," European Journal of Wood and Wood Products 73(6), 841-844. DOI: 10.1007/s00107-015-0935-8 
Laireiter, C. M., Schnabel, T., Köck, A., Stalzer, P., Petutschnigg, A., Oostingh, G. J., and Hell, M. (2014). "Active anti-microbial effects of larch and pine wood on four bacterial strains," BioResources 9(1), 273-281. DOI: 10.15376/biores.9.1.273-281

Li, X., He, C., Song, L., Li, T., Cui, S., Zhang, L., and Jia, Y. (2017). "Antimicrobial activity and mechanism of Larch bark procyanidins against Staphylococcus aureus," Acta Biochimica et Biophysica Sinica 49(12), 1058-1066. DOI: 10.1093/abbs/gmx112

Novaković, M., Novaković, I., Cvetković, M., Sladić, D., and Tešević, V. (2015). "Antimicrobial activity of the diarylheptanoids from the black and green alder," Brazilian Journal of Botany 38(3), 441-446. DOI: 10.1007/s40415-015-0151-0

Padmawar, A., and Bhadoriya, U. (2018). "Glycol and glycerin: Pivotal role in herbal industry as solvent/co-solvent," World Journal of Pharmaceutical and Medical Research 4(5), 153-155.

Plumed-Ferrer, C., Väkeväinen, K., Komulainen, H., Rautiainen, M., Smeds, A., Raitanen, J. E., Eklund, P., Willför, S., Alakomi, H. L., Saarela, M., et al. (2013). "The antimicrobial effects of wood-associated polyphenols on food pathogens and spoilage organisms," International Journal of Food Microbiology 164(1), 99-107. DOI: 10.1016/j.ijfoodmicro.2013.04.001

Ravber, M., Knez, Z., and Skerget, M. (2015). "Isolation of phenolic compounds from larch wood waste using pressurized hot water: Extraction, analysis and economic evaluation," Cellulose 22, 3359-3375. DOI: 10.1007/s10570-015-0719-7

Roy, D., Knapp, J. S., Guthrie, J. T., and Perrier, S. (2008). "Antibacterial cellulose fiber via RAFT surface graft polymerization,” Biomacromolecules 9(1), 91-99. DOI: $10.1021 / \mathrm{bm} 700849 \mathrm{j}$

Scheffler, A. (2019). "The wound healing properties of betulin from birch bark from bench to bedside," Planta Medica 85(7), 524-527. DOI: 10.1055/a-0850-0224

Schwieger-Briel, A., Ott, H., Kiritsi, D., Laszcyk-Laue, M., Bodemer, C. (2019). "Mechanism of Oleogel-S10: A triterpene preparation for the treatment of epidermolysis bullosa," Dermatologic Therapy 32(4). DOI: 10.1111/dth.12983

Smith, K. E. C., Oostingh, G. J., and Mayer, P. (2010). "Passive dosing for producing defined and constant exposure of hydrophobic organic compounds during in vitro toxicity tests," Chemical Research in Toxicology 23(1), 55-65. DOI: 10.1021/tx900274j

Soares, V. M., Pereira, J. G., Viana, C., Izidoro, T. B., Bersot, L. D. S., and Pinto, J. P. d. A. N. (2012). "Transfer of Salmonella enteritidis to four types of surfaces after cleaning procedures and cross-contamination to tomatoes," Food Microbiology 30(2), 453-456. DOI: 10.1016/j.fm.2011.12.028

Stern, T., Ranacher, L., Mair, C., Berghäll, S., Lähtinen, K., and Forsblom, M. (2018). "Perceptions on the importance of forest sector innovations: Biofuels, biomaterials, or niche products?," Forests 9(5), 255-268. DOI: 10.3390/f9050255

Timm, M., Saaby, L., Moesby, L., and Hansen, E. W. (2013). "Considerations regarding use of solvents in in vitro cell based assays," Cytotechnology 65(5), 887-894. DOI: 10.1007/s10616-012-9530-6

Vainio-Kaila, T., Kyyhkynen, A., Rautkari, L., and Siitonen, A. (2015). “Antibacterial effects of extracts of Pinus sylvestris and Picea abies against Staphylococcus aureus, Enterococcus faecalis, Escherichia coli, and Streptococcus pneumoniae," BioResources 10(4), 7763-7771. DOI: 10.15376/biores.10.4.7763-7771 
Vainio-Kaila, T., Zhang, X., Hänninen, T., Kyyhkynen, A., Johansson, L. S., Willför, S., Österberg, M., Siitonen, A., and Rautkari, L. (2017). "Antibacterial effects of wood structural components and extractives from Pinus sylvestris and Picea abies on methicillin-resistant Staphylococcus aureus and Escherichia coli O157:H7," BioResources 12(4), 7601-7614. DOI: 10.15376/biores.12.4.7601-7614

Wagner, K., Roth, C., Willför, S., Musso, M., Petutschnigg, A., Oostingh, G. J., and Schnabel, T. (2019). "Identification of antimicrobial compounds in different hydrophilic larch bark extracts," BioResources 14(3), 5807-5815. DOI: 10.15376/biores.14.3.5807-5815

Article submitted: January 21, 2020; Peer review completed: March 14, 2020; Revised version received and accepted: March 19, 2020; Published: March 25, 2020.

DOI: 10.15376/biores.15.2.3368-3381 